Prepared for the U.S. Department of Energy under Contract DE-AC05-76RL01830

\title{
Safeguards Culture
}

\author{
SL. Frazar \\ SV Mladineo
}

July 2012

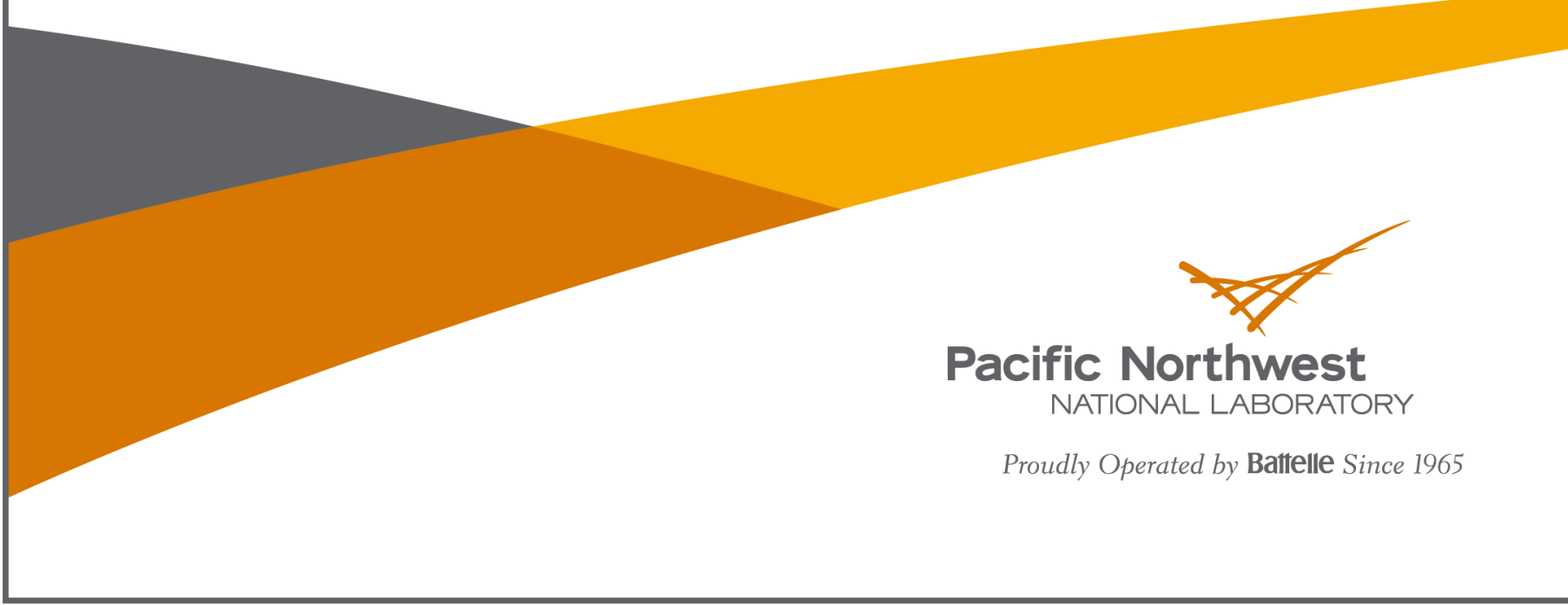




\title{
DISCLAIMER
}

This report was prepared as an account of work sponsored by an agency of the United States Government. Neither the United States Government nor any agency thereof, nor Battelle Memorial Institute, nor any of their employees, makes any warranty, express or implied, or assumes any legal liability or responsibility for the accuracy, completeness, or usefulness of any information, apparatus, product, or process disclosed, or represents that its use would not infringe privately owned rights. Reference herein to any specific commercial product, process, or service by trade name, trademark, manufacturer, or otherwise does not necessarily constitute or imply its endorsement, recommendation, or favoring by the United States Government or any agency thereof, or Battelle Memorial Institute. The views and opinions of authors expressed herein do not necessarily state or reflect those of the United States Government or any agency thereof.

\author{
PACIFIC NORTHWEST NATIONAL LABORATORY \\ operated by \\ BATTELLE \\ for the \\ UNITED STATES DEPARTMENT OF ENERGY \\ under Contract DE-AC05-76RL01830
}

Printed in the United States of America
Available to DOE and DOE contractors from the Office of Scientific and Technical Information,
P.O. Box 62, Oak Ridge, TN 37831-0062;
ph: (865) 576-8401
fax: $(865) 576-5728$
email: reports@adonis.osti.gov
Available to the public from the National Technical Information Service 5301 Shawnee Rd., Alexandria, VA 22312 ph: (800) 553-NTIS (6847)
email: orders@ntis.gov <http://www.ntis.gov/about/form.aspx>
Online ordering: http://www.ntis.gov

This document was printed on recycled paper. 
PNNL-21555

\title{
Safeguards Culture
}

\author{
SL Frazar \\ SV Mladineo
}

July 2012

Prepared for

the U.S. Department of Energy

under Contract DE-AC05-76RL01830

Pacific Northwest National Laboratory

Richland, Washington 99352 



\begin{abstract}
The concepts of nuclear safety and security culture are well established; however, a common understanding of safeguards culture is not internationally recognized. Supported by the National Nuclear Security Administration, the authors prepared this report, an analysis of the concept of safeguards culture, and gauged its value to the safeguards community. The authors explored distinctions between safeguards culture, safeguards compliance, and safeguards performance, and evaluated synergies and differences between safeguards culture and safety/security culture. The report concludes with suggested next steps.
\end{abstract}





\section{Executive Summary}

Historically, cultural indicators have not played a role in the International Atomic Energy Agency (IAEA, Agency) safeguards verification activities. In the past, the IAEA has followed a criteria-based approach to safeguards verification, relying on technical information that defined the scope, frequency, and the extent of the verification activities needed to achieve the inspection goals for each type of facility. Cultural indicators, which are inherently subjective and potentially discriminatory, played no role in these activities.

With the introduction of the Additional Protocol, the IAEA began exploring ways to move away from this criteria-based approach to an approach that allowed the IAEA to consider technical and non-technical data. The Agency's aim began shifting to achieve verification objectives for the State as a whole, using all information available to the IAEA. Recognizing this shift in thinking, there may be value in considering whether indicators of a State's safeguards culture could provide useful information for what is now being developed into the State-level approach.

Our analysis begins with the hypothesis that indicators of a State's safeguards culture can inform the IAEA about the State's safeguards program, and that this information could be used to improve a State's safeguards performance. We introduce the concept of organizational culture to provide theoretical underpinnings for culture evaluations. We explore the meaning of safeguards culture and potential indicators of its status. We examine the relationship among safeguards culture, safety culture, and security culture, and consider potential definitions for safeguards culture.

We conducted an extensive review of the literature on safeguards culture. There has been limited discussion of safeguards culture, particularly when compared with safety culture or nuclear security culture. However there has been extensive use of the term safeguards culture by international safeguards experts, including members of the Standing Advisory Group on Safeguards Implementation (SAGSI) and by IAEA and other safeguards professionals.

A safeguards culture exists in every State. Most references in the literature seem to recognize it as an idea (phenomenon) that should be advanced or strengthened. This acceptance of the concept is noteworthy since there has been little history of analyzing safeguards culture or identifying indicators to measure it. We infer that those who use the term assume an intuitive understanding of the meaning of safeguards culture and its contribution to international safeguards.

Another recurring issue in the literature is the simultaneous, and therefore imprecise, reference to the first two senses or usages of the term safeguards culture. Where an author makes a distinction between the safeguards culture within a member State and the IAEA's safeguards culture, it may be in the form of a question as to which of the two meanings the term should address.

Some authors assert the importance of examining safeguards culture in conjunction with safety and security cultures. This body of work is significant since there is some implication that the importance of safeguards culture may be most profound when viewed not in isolation, but in connection with the other disciplines. In these discussions, safeguards culture is viewed as part of a system that has particular importance to States that are taking on new safeguards obligations such as nuclear newcomer States or 
recent signatories of an Additional Protocol. In these cases the authors cited argue that there is an opportunity to integrate the three cultures early in the State's infrastructure development process.

Culture is generally defined as the behaviors and beliefs characteristic of a particular group. Several characteristics of culture include shared beliefs, values and attitudes; shared knowledge and values; and predominating attitudes that characterize the functioning of a group or organization. While these characteristics may be considered fuzzy, imprecise, and non-quantitative, scholars have demonstrated practical applications of culture. The study cites the example of Edgar Schein's work in applying a methodology to organizational culture that we apply to our consideration of safeguards culture.

Schein's model serves as a conceptual underpinning for our investigation of safeguards culture. To frame our investigation of safeguards culture, and set the stage for a discussion about potential definitions of the term, we explore four central themes and fundamental questions.

- What does safeguards culture mean and how does it contribute to the international safeguards system?

Further exploration of safeguards culture should begin with achieving an international consensus on a definition for the concept. This should be followed by development of a rigorous methodology for identifying indicators of safeguards culture and establishing the causal link between beliefs or attitudes and safeguards actions. These indicators should offer the IAEA objective, factually-based information that does not discriminate among States. This conceptual development will help inform establishment of a clear definition for safeguards culture, which is necessary to advance discussion among Member States and promote good practices that improve safeguards performance.

As we discuss in this study, the meaning of safeguards culture may be most useful when applied to States with, a robust regulatory system. The value of safeguards culture may be in its ability to differentiate between States that are compliant from those that are considered high-performing. For example, due to a shortage of resources or a belief that there are higher priorities that need to be addressed, a facility may choose not to provide advanced training to staff on safeguards techniques, such as conducting high-quality measurements of nuclear material. As another example, one facility may perceive self-assessments to be a drain on resources. In these cases, such beliefs and values may lead staff personnel to place a low priority on activities that enhance their ability to comply with laws and regulations more effectively and efficiently. These beliefs translate to a weakened safeguards culture and poor compliance with what may otherwise be a robust nuclear regulatory system.

On the other hand, there are additional drivers such as international prestige, technological sophistication, customs, mores, leadership, fears and values, among others, for performing safeguards functions well. A strong safeguards culture is one in which the beliefs, values, and attitudes toward international safeguards are manifested in better performance. High-performing facility and regulatory staff are less likely to generate errors, inaccuracies, or inconsistencies in their reporting to the IAEA, making IAEA inspections and evaluations, and thus safeguards implementation more effective and efficient.

- What are the indicators of its existence?

We propose a refined set of sample indicators of safeguards culture within Member States. Further research and international consensus is necessary to determine a complete set of appropriate indicators that can differentiate among states without being discriminatory. However, for purposes of 
this paper, the authors present a set of sample indicators to suggest that it is possible to identify indicators of safeguards culture.

- How might safeguards culture develop or be promoted?

The benefit of clarifying a definition for safeguards culture and creating a framework for thinking about it is that the framework could be used to identify methods for promoting a strong safeguards culture within a Member State. We provide a list that includes a number of activities that could be pursued by a State (or promoted by third parties) to develop a strong safeguards culture within a State.

- What is the relationship between safeguards culture, safety culture and security culture?

We conclude our analysis of safeguards culture with an examination of its relatively slower development, as compared to nuclear safety culture and nuclear security culture. We explore the similarities and differences between each concept's development to help explain why safeguards culture as a concept has not matured, despite a number of noncompliance-related activities that might otherwise have driven further development of the concept.

We believe that perceived risk plays a critical role in the evolutionary process. As the world became more knowledgeable and experienced with operating nuclear power plants, countries became more cognizant of the risks associated with a nuclear accident. In response, the nuclear industry began strengthening nuclear regulations to mitigate the risks. In conjunction, they began considering ways to cultivate a culture that promotes greater appreciation and commitment to nuclear safety.

This perception of risk has played a similar role in the debate about whether to define and promote safeguards culture. The perceived risk to an individual from the diversion of nuclear materials or clandestine development of nuclear capabilities is comparatively low. This may explain why some noncompliance events, which might have been expected to promote stronger safeguards cultures, have not created a groundswell of support for paying attention to the safeguards culture. As long as safeguards culture was linked to risk and by extension noncompliance, its further development and promotion would be unlikely.

However, mission effectiveness and efficiency are becoming equal priorities with risk mitigation, both within Member States developing nuclear power and within the IAEA. The IAEA has discovered that it cannot perform all of its responsibilities without introducing more efficiency into its operations, and nuclear newcomer States are learning that weak adherence to regulations, poor quality measurements, untrained staff, limited cooperation with the IAEA, and inaccurate accounting and operating records can all lead to an increase in IAEA scrutiny and greater intrusion in facility operations. Consequently, States are starting to assess the cost-effectiveness of optimizing organizational operations through the integration of complementary components of safety, security, and safeguards systems. Further scrutiny may reveal that consideration of $3 \mathrm{~S}$ culture would provide new ways of promoting safeguards, safety, and security.

Building upon the internationally accepted definitions of safety culture and nuclear security culture, several authors have proposed definitions for safeguards culture. For example, Kaoru Naito argues that the definition of safety culture emphasizes its overriding priority, and the definition of nuclear security culture is silent about the relative priorities among nuclear security, safeguards, public acceptance, transparency and other factors. With this in mind, he writes that it is hard to say that nuclear security 
should have overriding priority and that this may hold true for safeguards. He proposes to define safeguards culture after nuclear security culture:

"The assembly of characteristics, attitudes and behavior of individuals, organizations and institutions which serves as a means to support and enhance safeguards or to achieve effective and efficient safeguards."

Naito's definition focuses on the IAEA mission (effective and efficient safeguards), but it also has the State-level safeguards culture component (support and enhance safeguards). By parsing his definition, we can clarify the difference between the two senses or usages of safeguards culture. Consequently there may be merit in considering a separate definition for IAEA safeguards culture, such as:

"A shared belief by IAEA safeguards authorities, inspectors, and analysts that the people, processes, and procedures used by the IAEA to draw safeguards conclusions are effective and efficient."

Further exploration of safeguards culture should begin with achieving an international consensus on a definition for the concept. This should be followed by development of a rigorous methodology for identifying indicators of safeguards culture and establishing the causal link between beliefs or attitudes and safeguards actions. These indicators should offer the IAEA objective, factually based information that does not discriminate among States. This conceptual development will help inform establishment of a clear definition for safeguards culture, which is necessary to advance discussion among Member States and promote good practices that improve safeguards performance.

\section{Acknowledgements}

The authors wish to acknowledge the valuable insights and contributions of Mr. Jonathan Essner of Lawrence Livermore National Laboratory. 


\section{Acronyms and Abbreviations}

Agency

ESARDA

IAEA

INMM

INSAG

NGSI

NNSA

PNNL

SAGSI

SSAC
International Atomic Energy Agency

European Safeguards Research and Development Association

International Atomic Energy Agency

International Nuclear Materials Management

International Nuclear Safety Advisory Group

Next Generation Safeguards Initiative

National Nuclear Security Administration

Pacific Northwest National Laboratory

Standing Advisory Group on Safeguards Implementation

State Systems of Accounting for and Control of Nuclear Materials 



\section{Contents}

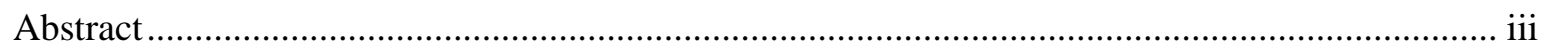

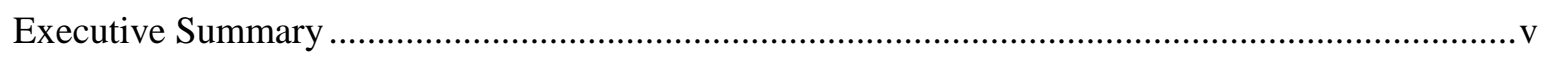

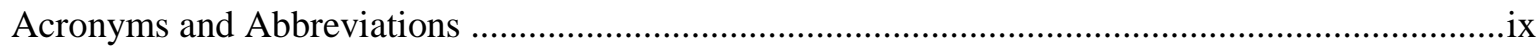

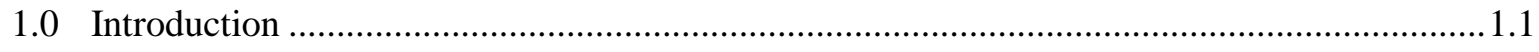

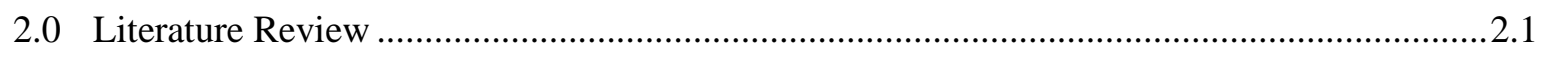

2.1 Literature Asserting the Importance of Safeguards Culture ...........................................2.2

2.2 Literature Citing Examples of Different Senses of Safeguards Culture ........................2.2

2.3 Literature Espousing the Synergies Among Safeguards, Safety, and Security Culture ..2.4

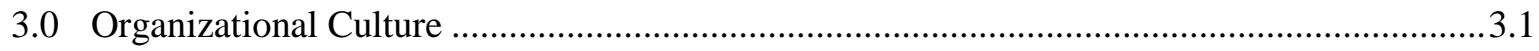

$4.0 \quad$ Analysis .................................................................................................................. 4.1

4.1 What Does Safeguards Culture Mean and How Does it Contribute to the International Safeguards System?............................................................................................ 4.1

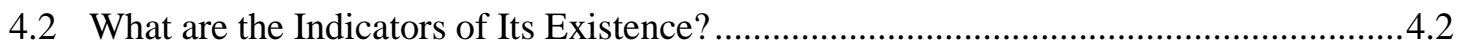

4.2.1 Safeguards Culture within the State ............................................................... 4.3

4.2.2 Safeguards Culture within the IAEA.............................................................4.4

4.3 How might safeguards culture develop or be promoted? ............................................ 4.5

4.4 What is the relationship between safeguards culture, safety culture and security

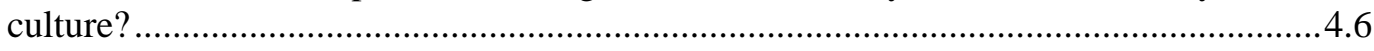

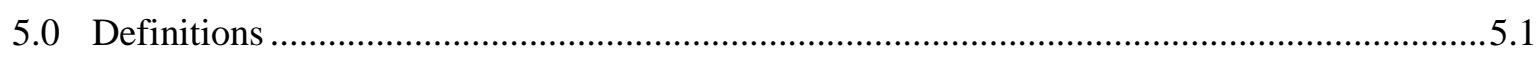

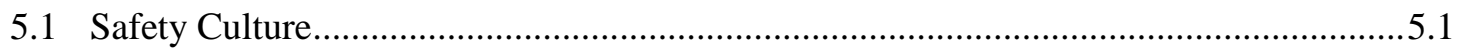

5.1 .1 Nuclear Security Culture …........................................................................ 5.1

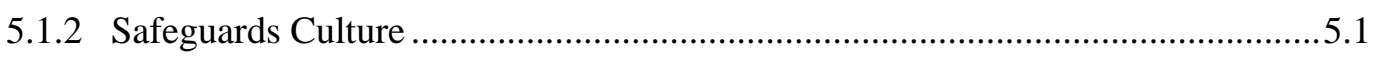

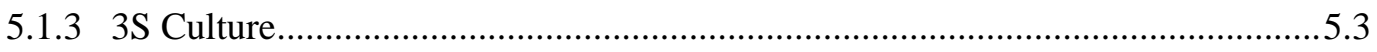

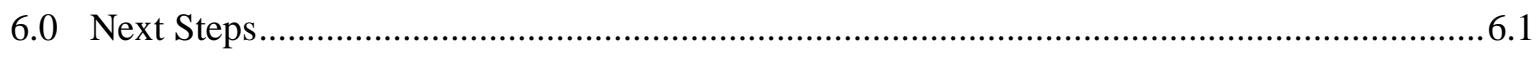

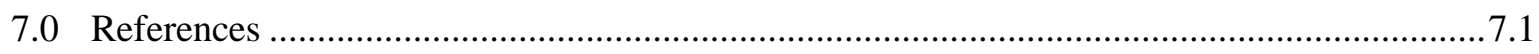




\section{Figures}

Figure 3.1. Schein's Model of Organizational Culture 3.1

\section{Tables}

Table 4.1. Sample Indicators of Safeguards Culture within a Member State ...............................4.4

Table 4.2. Sample Indicators of the Evolving Safeguards Culture at the IAEA ............................4.5

Table 4.3. Sample Indicators of Safeguards Culture with Promotional Activities ........................4.6 


\subsection{Introduction}

Historically, cultural indicators have not played a role in the International Atomic Energy Agency (IAEA, Agency) safeguards verification activities. In the past, the IAEA has followed a criteria-based approach to safeguards verification, relying on technical information that defined the scope, frequency, and the extent of the verification activities needed to achieve the inspection goals for each type of facility. Cultural indicators, which are inherently subjective and potentially discriminatory, played no role in these activities.

After the surprises revealed by the first war in Iraq, the IAEA started evolving, changing the way it did business. With the introduction of the Additional Protocol, the IAEA began exploring ways to move away from this criteria-based approach to an approach that allowed the IAEA to consider technical and non-technical data. The Agency's aim began shifting to achieve verification objectives for the State as a whole, using all information available to the IAEA. Recognizing this shift in thinking, there may be value in considering whether indicators of a State's safeguards culture could provide useful information for what is now being developed into the State-level approach. Specifically, would additional information about a State's beliefs and behaviors as they pertain to safeguards add value to the existing technical and non-technical data the IAEA has about a State's nuclear program? Clearly, the IAEA could not rely solely on cultural data to draw its safeguards conclusions. However, information and data about a State or facility's safeguards attitudes and behaviors may provide a deeper understanding about how safeguards are implemented in a State and why certain problems might be occurring. For example, an unwillingness to invest money or time in maintenance of State Systems of Accounting for and Control of Nuclear Materials (SSAC) reporting methods or staff training could manifest itself in an increase in questions or anomalies that arise during safeguards inspections. General apathy toward safeguards among facility staff could be manifested in inaccurate nuclear material accountancy reporting or by poor quality measurements.

Without a rigorous methodology, it would be difficult, if not impossible, to establish a causal link between a belief or an attitude such as apathy with a safeguards action such as inaccurate reporting. However, if a rigorous methodology could be developed, it might be possible to determine how cultural factors differentiate compliant States from high-performing States. A State with a weak safeguards culture may be complying with its safeguards requirements but performing at a level that does not preclude problems or questions from arising and hindering IAEA conclusions.

The first step in determining whether a methodology could be developed is defining which cultural indicators might offer the most valuable, objective, and non-discriminatory information to the IAEA. Then, it must be determined whether those indicators could link a State or individual's beliefs and intentions about safeguards to specific actions. This paper is intended to explore these issues and help inform a clear definition for safeguards culture. Further clarification of the concept will help advance discussion on the topic and possibly lead to the promotion of good practices that improve safeguards performance in Member States.

Other disciplines have pursued this conceptual process with some success, although it took eight consultants' meetings and one technical meeting at the IAEA, over several years, to develop an internationally agreed-upon definition for security culture, and to produce a guidelines document on the subject. Nuclear safety and nuclear security professionals have identified indicators that link activities, 
beliefs, and intentions to actions, thus enabling inferences to be drawn about the integrity of the safety or nuclear security culture within the State. Consequently, over time, and with Agency leadership, internationally accepted definitions of safety culture and security culture were agreed upon, with emphasis on the characteristics, attitudes, and behavior that promote good safety and nuclear security practices. This process of conceptual development and definition has not yet occurred for safeguards culture, despite events that might have been expected to advance the issue, including, principally, safeguards compliance issues in numerous states. Thus, understanding why the concept of safeguards culture has not evolved in the same way as safety culture and nuclear security culture will be an important part of the development process.

To evaluate the value and role of safeguards culture, the Office of Nuclear Safeguards and Security at the National Nuclear Security Administration (NNSA) asked the Pacific Northwest National Laboratory (PNNL) to prepare an analysis of the concept of safeguards culture. Our analysis begins with the hypothesis that indicators of a State's safeguards culture can inform the IAEA about the State's safeguards program, and that this information could be used to improve a State's safeguards performance. We introduce the concept of organizational culture to provide theoretical underpinnings for culture evaluations. We explore the meaning of safeguards culture and potential indicators of its status. We examine the relationship among safeguards culture, safety culture, and security culture, and consider potential definitions for safeguards culture. 


\subsection{Literature Review}

The breadth of literature on the topic of safeguards culture is limited, compared to the expansive literature on safety culture and, more recently, nuclear security culture. The term is generally used in one of three ways. In the first sense, it is used to describe the attitudes and beliefs within the IAEA, as the Agency evolves its approach to safeguards evaluation from a criteria-based approach to an informationdriven approach. In the second sense, it deals with assessing a State's commitment to nonproliferation obligations and its active cooperation with safeguards authorities. In the third sense, not discussed in this paper, it refers to the culture of domestic safeguards and security within a State. For purposes of clarity, we will focus on the first two usages, with most of the attention on the second usage, addressing the concept within a State.

Only a few authors have written about safeguards culture in some capacity. Among these are two of the three authors of this study. While it may seem disingenuous for the authors to quote their own work, we think it is necessary because of the limited literature on the topic. We have taken pains to avoid simply ratifying any advocacy positions taken in those previous works.

In reporting the results of the literature review, we note the frequent use of the term safeguards culture by members and former members of the Standing Advisory Group on Safeguards Implementation (SAGSI) and by IAEA and other Safeguards professionals. As we recount later, John Carlson, the former director of the Australian Safeguards Office and a former member of the SAGSI, has used the term frequently in speeches. Former SAGSI Member Kaoru Naito of the Nuclear Material Control Center in Japan has advocated for the SAGSI to develop a definition for safeguards culture. Jill Cooley of the IAEA has discussed the use of the term particularly as it relates to changes at the IAEA.

As noted in the introduction, a safeguards culture exists in every State. Most references in the literature seem to recognize it as an idea (phenomenon) that should be advanced or strengthened. This acceptance of the concept is noteworthy since there has been little history of analyzing safeguards culture or identifying indicators to measure it. We infer that those who use the term assume an intuitive understanding of the meaning of safeguards culture and its contribution to international safeguards.

Another recurring issue in the literature is the simultaneous, and therefore imprecise, reference to the first two senses or usages of the term safeguards culture. Where an author makes a distinction between the safeguards culture within a member State and the IAEA's safeguards culture, it may be in the form of a question as to which of the two meanings the term should address.

Some authors assert the importance of examining safeguards culture in conjunction with safety and security cultures. This body of work is significant since there is some implication that the importance of safeguards culture may be most profound when viewed not in isolation, but in connection with the other disciplines. In these discussions, safeguards culture is viewed as part of a system that has particular importance to States that are taking on new safeguards obligations such as nuclear newcomer States or recent signatories of an Additional Protocol. In these cases the authors cited argue that there is an opportunity to integrate the three cultures early in the State's infrastructure development process. 


\subsection{Literature Asserting the Importance of Safeguards Culture}

In the 2005 Institute of Nuclear Materials Management/European Safeguards Research and Development Association (INMM/ESARDA) Workshop, "Changing the Safeguards culture: Broader Perspectives and Challenges," Jill Cooley and Roger Howsley, then of British Nuclear Fuels Limited, reported: "It is clear that 'safeguards culture' needs to be addressed if the efficiency and effectiveness are to continue to be improved. This will require commitment and change at all levels, from States to facility operators. Cultural change has to come from good leadership, doing the right thing and 'beliefs' are not sufficient - behavior is what counts. We are optimistic that with sufficient effort and the right incentives, change can be accomplished quickly."

In her presentation at the 2010 Safeguards Symposium, Sonia Fernández Moreno of the Argentine Nuclear Regulatory Authority suggested that the Safeguards and international community need to work towards establishing a safeguards culture (Moreno 2010).

U.M. Mirsaidov, from the Tajikistan Nuclear Radiation Authority, added: "Exclusive importance for IAEA safeguards agreement is high safeguards culture. IAEA should regularly conduct seminars on advanced assessment of safeguards culture - exactly as recommends to nuclear sites regularly to assess safety culture, and to undertake steps on elimination of any revealed shortcomings." (Mirsaidov 2010).

Asserting the importance of safeguards culture at the 31st meeting of ESARDA, Stephen Mladineo suggested methods of implementing a safeguards culture and a definition (Mladineo 2009). Frazar and Mladineo (2010b) published an expanded version of the Vilnius paper in the ESARDA Bulletin, where they introduced the idea of measuring safeguards culture.

At the 50th Annual INMM meeting, Carlson (2010) spoke about strengthening safeguards through regional cooperation. In his remarks about the Asia-Pacific Safeguards Network (ASPN), he noted that building a safeguards culture was an important, but challenging, responsibility for the organization:

"One of the most important responsibilities for APSN will be to contribute to building a non-proliferation and safeguards culture in the Asia-Pacific region... A safeguards culture will provide a strong foundation for the future development of safeguards practice in the region, ensuring there is a regional approach, shared professional standards and values. A safeguards culture will strengthen safeguards as a regional confidence-building and transparency mechanism. A strategic approach is needed - what is meant by a 'safeguards culture'? What are the qualities to build and encourage? How to develop a safeguards culture and how to promote it? These are not easy questions. "

\subsection{Literature Citing Examples of Different Senses of Safeguards Culture}

Several authors discuss safeguards culture as applied to Member States or to the IAEA, while others discuss the term in both contexts simultaneously without distinguishing between the two. This is a significant recurring issue in the literature because it lies at the heart of the discussion about the meaning of safeguards culture and its potential importance to international safeguards. Attempts to provide a single definition of the concept may resolve only some of the questions surrounding the concept. Two 
different definitions may be needed for the term: one that is used when discussing Member States and one that is used when discussing the internal culture at the IAEA.

For example, Carlson (2005) sometimes invokes each context in his speeches and writings.

"Safeguards culture is usually thought of in terms of the internal IAEA culture, in particular the approach towards safeguards implementation. Safeguards culture is a product of its institutional context - the terms and interpretation of the relevant treaties and agreements; the available verification methodologies; the shared attitudes and values of the Agency; recruitment, training and retention of inspection staff; management practices; and so on. Safeguards culture therefore is influenced not only [by] the safeguards staff, but by other areas of the Agency. Safeguards culture is also influenced by Member States - at both diplomatic and SSAC level."

In his closing address at the Safeguards Symposium in Vienna, Carlson discussed the term exclusively in the context of the IAEA (Persbo 2012): "Building support for the safeguards mission involved a variety of factors, including the promotion of a shared safeguards culture, greater communication and outreach efforts, greater transparency on the part of the Agency as to the costs of safeguards implementation and - following that - a need to address the funding problems constraining the IAEA's safeguards work."

Others have discussed the concept in terms of assessing or promoting Member State commitment to nonproliferation. For example, in June 2008 then-NNSA Associate Deputy Administrator Adam Scheinman (2008) discussed the importance of: "[promoting] a safeguards culture through infrastructure development." In 2009, at the Second International Meeting on Next Generation Safeguards, NNSA Administrator Thomas D'Agostino (2009) reported that the Next Generation Safeguards Initiative (NGSI), which was established to strengthen the international safeguards system, was: “... helping to build a safeguards culture in countries pursuing nuclear power." At the same meeting, Shunsuke Kondo (2009), Chairman, Japan Atomic Energy Commission, reiterated D'Agostino's point by stating: “I would like to stress the importance of maintaining and reinforcing social environment for taking the safeguards seriously. Governments and the organizations involved in the regulation and promotion of research, development and utilization of nuclear energy should review the pervasiveness of safeguards culture among leaders, senior managers and operating personnel of facilities and institutions concerned."

Kaoru Naito noted the two usages of the term safeguards culture in his paper at the INMM/ESARDA Workshop in 2011 (Naito 2011). He analyzed the definition of safeguards culture, building upon the IAEA-defined concepts of safety culture and safeguards culture.

Expanding on the aforementioned work in the ESARDA Bulletin and elsewhere, Frazar and Mladineo (2010b) discussed the training of newcomer States in safeguards culture in their paper at the Pacific Northwest International Conference on Global Nuclear Security — the Decade Ahead in April 11-16, 2010 (Frazar and Mladineo 2010a). At the 51st INMM Annual Meeting, they then outlined a candidate measurement methodology for safeguards culture in a Member State (Frazar and Mladineo 2011a). Informal discussions at the INMM Annual Meeting with Jill Cooley suggested we consider applying the methodology to the safeguards culture of the IAEA. 


\subsection{Literature Espousing the Synergies Among Safeguards, Safety, and Security Culture}

There is a segment of the literature that highlights potential synergies among safeguards, safety, and security culture. As Scheinman (2009) noted in an article in the Nonproliferation Review, "The IAEA indicates that as many as fifty states have expressed interest in pursuing nuclear power. Given that only thirty-odd countries operate nuclear power reactors today, this would be a marked increase that would not only impose significant demands on IAEA safeguards resources, but also create opportunities to build a 'safeguards culture' on par with nuclear industry's 'safety culture.' Safety, safeguards, and security should in fact be linked, as endorsed by the Group of Eight at its last summit and in the IAEA 'Milestones' document guiding the development of national infrastructure for nuclear energy."

In a paper for the 50th INMM meeting, Don Kovacic from Oak Ridge National Laboratory and his co-authors argue for the development of a 3S (Safety, Security, and Safeguards) infrastructure for nuclear newcomer States and propose a definition for safeguards culture. They contend that while safety and security have analogues in other fields, international safeguards is unique to the nuclear industry. Therefore, to better incorporate it into the thinking of nuclear newcomer States, the subject of safeguards should be bundled with safety and security as three essential, related infrastructure requirements for the development of a nuclear program. They note that the work done by the NNSA International Nuclear Safeguards and Engagement Program (INSEP) has supported efforts to promote the development of a nuclear safeguards infrastructure, which may have the benefit of strengthening safeguards culture (Kovacic et al 2009).

In an article promoting the INSEP contribution to newcomer State training, John McClelland-Kerr of the NNSA and Rebecca Stevens from Los Alamos National Laboratory argue that the process of building (McClelland-Kerr and Stevens 2010)

“... safeguards infrastructure should be integrated with other critical elements of nuclear energy considerations, including safety and security ... Safeguards culture is a concept worth exploring in the context of building safeguards infrastructure. The promotion of safeguards culture has to do less with the implementation of various projects than with the parallel undertaking of promoting the priorities and behaviors that encourage a safeguards mentality. At the most basic level, for safeguards to take root and flourish, a culture that encourages it is necessary. Culture, as commonly used, denotes a set of shared values, objectives and practices that characterize a particular group. Safeguards culture, then, could be thought of in terms of similar principles such as the shared commitment to nonproliferation and the peaceful use of nuclear energy; a shared belief in the necessity of practices and expectations that provide complete assurance to the national authority, the IAEA and the world community regarding the declaration and use of nuclear material; and practices such as continual evaluation and organizational learning that improve the effectiveness of the overall system."

At the 51st INMM Meeting, Elina Martikka, of the Finnish Nuclear Regulatory Authority, presented a paper on the importance of safeguards by design and its connection to safety and security by design. There she emphasized the role of the SSAC in promoting a safeguards culture. She argues that the safeguards culture must go beyond the nuclear power plant operators (Martikka et al. 2011). “... it is still common that safeguards culture is acknowledged to cover the stakeholders at national, facility and 
individual levels in Member States, but not the designers, manufacturers and supply organisations that operate [in a] global market." She also reports that Finland will be changing its regulations in order to expand the application of safeguards culture beyond the current stakeholders.

At the First International Workshop on Safety and Security Risk Assessment and Organisational Cultures in January 2012, three papers touched on the topic of safeguards culture. Mladineo and Frazar (2012) linked organizational culture, 3S, and safeguards by design, arguing that safeguards culture will benefit from paying attention to safety, security, and safeguards together, particularly in newcomer States. Martikka (2012) argued that safeguards by design need to be implemented early in the design process for a new facility and that a focus on $3 \mathrm{~S}$ helps to strengthen the safeguards culture. Erzsébet Földesi from the Hungarian Atomic Energy Authority reported on the results of the first assessment of the safeguards culture of a utility. Among her conclusions was that the utility “... top management became more aware of its safeguards obligation .... and that nuclear safety and security culture are well respected and developed in Hungary. By improving the nuclear safeguards culture in the organization safeguards is expected to get the same importance as nuclear safety and security culture."

In a presentation at a conference discussing the pending Seoul Nuclear Summit, Carlson, in his new capacity as Counselor, Nuclear Threat Initiative, and Visiting Fellow, Lowy Institute, proposed (Carlson 2012): "Another concept that should be developed is a ' $3 S$ ' culture, a professional approach that draws together the disciplines of safeguards, safety and security and benefits from the synergies in these areas. A $3 \mathrm{~S}$ culture could be reflected not only in nuclear operations, but in governance arrangements, e.g., peer reviews that look at safeguards, safety and security, or safeguards inspectors that can advise on safety and security matters." Separately, Frazar and Mladineo (2011) argue that "recognizing the evolution of the various safeguards, safety and security culture discussions, it may be time to consider $3 \mathrm{~S}$ Culture as its own concept. Understanding how the three subcultures reinforce or undermine each other will contribute to the process of developing safe, secure and safeguarded nuclear infrastructures. A possible step forward could be to develop an IAEA guidelines document that defines and characterizes safeguards culture, with the possibility of a follow-on document to focus on 3 S Culture."

The authors were unable to identify a technical guidance document or other IAEA publication that examines the concept or significance of safeguards culture to international safeguards. This may be because of the absence of a rigorous methodology or clear definition for the concept that could serve as a foundation for such a document. 



\subsection{Organizational Culture}

The recurring themes in the literature on safeguards culture highlight the need or desire for a more precise, unambiguous definition. To explore definitions of safeguards culture, we must first determine whether culture in general has tangible qualities that can be measured and discussed in various settings. The following discussion describes scholarly efforts to demonstrate the practical applications of culture.

Culture is generally defined as the behaviors and beliefs characteristic of a particular group. Several characteristics of culture include shared beliefs, values and attitudes; shared knowledge; and predominating attitudes that characterize the functioning of a group or organization. While these characteristics may be considered fuzzy, imprecise, and non-quantitative, scholars have demonstrated practical applications of culture. One such scholar, Edgar Schein from the Sloan School of Management at MIT, has published extensively on the notion of organizational culture as a way to talk about the tangible qualities of culture. Schein (1997) provides the following definition of organizational culture:

"A pattern of shared basic assumptions that was learned by a group as it solved its problems of external adaptation and internal integration, that has worked well enough to be considered valid and, therefore, to be taught to new members as the correct way you perceive, think, and feel in relation to those problems."

Schein's model of organizational culture is often depicted as a triangle with artifacts at the top (Figure 1), espoused values in the middle, and underlying assumptions at the base. The underlying assumptions and beliefs of the organization enable staff to understand the organization's raison d'etre, its mission and their role within that organization. These assumptions and beliefs are reflected in the espoused values, which are passed down within the organization in the form of policy documents, instructions, guidelines, and orders and reinforced through qualification certificates, performance evaluations and praise, self-audits, and training workshops. The resulting artifacts are the statements and activities communicated and performed by the organization and its staff, telling others about the espoused values and underlying assumptions and beliefs of that organization.

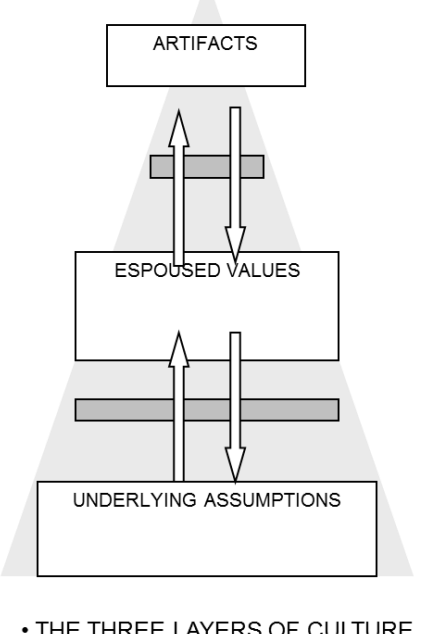

Figure 3.1. Schein's Model of Organizational Culture 
In short, people's statements and actions are demonstrations of things outsiders might only guess about, the individual and shared assumptions, values, and beliefs of that organization's culture. This message, along with Schein's model, can be extrapolated to the context of safeguards culture. 


\subsection{Analysis}

Schein's model serves as a conceptual underpinning for our investigation of safeguards culture. To frame our investigation of safeguards culture, and set the stage for a discussion about potential definitions of the term, we explore four central themes and fundamental questions.

- What does safeguards culture mean and how does it contribute to the international safeguards system?

- What are the indicators of its existence?

- How might safeguards culture develop or be promoted?

- What is the relationship between safeguards culture, safety culture and security culture?

\subsection{What Does Safeguards Culture Mean and How Does it Contribute to the International Safeguards System?}

The literature review revealed different uses of the same term: one for the safeguards culture within a State and one for the safeguards culture within the IAEA. We will begin with the meaning and value of safeguards culture within a State.

To implement international safeguards within a State, safeguards laws, regulations, and international requirements are primary drivers of operator behavior. Operators within the State perform safeguards functions and comply with safeguards laws and requirements because they prescribe or restrict certain types of behavior. Inspections and investigations followed by written notices, fines, and reports to the IAEA Board of Governors for noncompliance help enforce fulfillment of laws, regulations, and requirements.

In some cases, even the most robust regulatory systems are not enough to ensure adequate attention to safeguards requirements. For example, because of a shortage of resources or a belief that there are higher priorities that need to be addressed, a facility may choose not to provide advanced training to staff on safeguards techniques, such as conducting high-quality measurements of nuclear material. As another example, one facility may perceive self-assessments to be a drain on resources. Others may see international safeguards as an affront to State sovereignty. In these cases, such beliefs and values may lead staff personnel to place a low priority on activities that enhance their ability to comply with laws and regulations more effectively and efficiently. These beliefs translate to a weakened safeguards culture and poor compliance with what may otherwise be a robust nuclear regulatory system.

On the other hand, there are additional drivers such as international prestige, technological sophistication, customs, mores, leadership, fears and values, among others, for performing safeguards functions well. A strong safeguards culture is one in which the beliefs, values, and attitudes toward international safeguards are manifested in better performance. High-performing facility and regulatory staff are less likely to generate errors, inaccuracies, or inconsistencies in their reporting to the IAEA, making IAEA inspections and evaluations, and thus safeguards implementation more effective and efficient.

Based on these high-level characterizations, one could argue that a State with a strong safeguards culture has the following characteristics: 
- a Comprehensive Safeguards Agreement and Additional Protocol in force

- meets all of its safeguards requirements through accurate and complete safeguards reporting,

- has few or no inconsistencies in its reporting, and

- consistently supports IAEA activities.

International inspections run smoothly, questions are addressed promptly and the IAEA can reach a safeguards conclusion without expenditure of resources that are beyond the expected budget.

A State with an underdeveloped safeguards culture may have the following characteristics:

- a Comprehensive Safeguards Agreement is in force

- meets its safeguards requirements but with inaccuracies and inconsistencies in reporting

- $\quad$ provides sporadic support for IAEA inspections

- has no history of noncompliance.

International inspections waste resources investigating reporting errors and anomalies due to clerical errors or other innocent mistakes, exceeding allocated budgets. There are indications that safeguards staff do the bare minimum to meet their international requirements but could do more to increase the effectiveness or efficiency of their safeguards reporting. To perform at a higher level, staff may need additional technical training, better equipment, or more information about the importance of safeguards implementation.

Finally, A State with a weak safeguards culture may have the following characteristics:

- a Comprehensive Safeguards Agreement is in force,

- does not meet its safeguards requirements, and

- offers sporadic support for, or hinders IAEA inspections.

Taking this example a step farther, the subject of safeguards culture may be completely irrelevant in a non-cooperative State. A State that is not compliant with its safeguards obligations is clearly exhibiting behaviors that make consideration of indicators of safeguards culture moot.

The ability to make these characterizations about a State's safeguards culture reflects a deeper, more nuanced understanding of why certain performance problems may be occurring in a State and enables the IAEA to focus its resources on the areas where it can have the most impact, such as additional training, technical assistance or equipment procurement.

\subsection{What are the Indicators of Its Existence?}

While we have not addressed the State Level Concept in this discussion, the development of a set of indicators and a methodology for use by the IAEA might support the burgeoning concept. According to Jill Cooley, in conducting a State Evaluation, the IAEA considers State-specific factors. These are described as relevant, factual characteristics of a State that may influence the planning, conduct or 
evaluation of safeguards activities for a State. They may be both technical and non-technical in nature (Cooley 2011). "Examples of such factors include: the State's legal framework for implementing safeguards obligations; nuclear fuel cycle activities and material; history of safeguards implementation for the State; and the nature of cooperation with the State. It is important to recognize that they are to be used as facts not for rating a State."

In order to differentiate without discriminating, consideration of these non-technical factors needs to be applied rigorously. To explore this further, this section will suggest potential indicators of safeguards culture first in Member States and then within the IAEA.

\subsubsection{Safeguards Culture within the State}

In 2011, Frazar and Mladineo proposed a number of indicators of safeguards culture. Table 4.1 presents a refined set of sample indicators of safeguards culture within Member States (Frazar and Mladineo 2011a). Further research and international consensus is necessary to determine a complete set of appropriate indicators that can differentiate among states without being discriminatory. However, for purposes of this paper, the authors present a set of sample indicators to suggest that it is possible to identify indicators of safeguards culture. 
Table 4.1. Sample Indicators of Safeguards Culture within a Member State

\begin{tabular}{|l|l|}
\hline Safeguards Culture Indicators \\
\hline - & $\begin{array}{l}\text { State has a Comprehensive Safeguards Agreement and Additional Protocol in force (if a Small } \\
\text { Quantities Protocol [SQP] is in force, it is the modified SQP). }\end{array}$ \\
\hline - & $\begin{array}{l}\text { Safeguards Regulatory Authority (SRA) is independent from organizations responsible for promoting } \\
\text { nuclear power. }\end{array}$ \\
\hline - & SRA conducts independent inspections \\
State and facilities perform regular self-assessments to identify and resolve issues and inconsistencies \\
before the official IAEA inspection. Corrective action mechanism/organizational improvement \\
mechanisms exist and are used
\end{tabular}

To generate this small sample set, we focused on indicators that likely would be driven by incentives other than mere compliance with national laws and regulations. For example, Mladineo and Frazar noted that mission enhancement is one compelling reason for implementing safeguards measures. As they stated (2011a), "When states and facilities perform voluntary activities regarding safeguards because such activities are seen to enhance the mission, this is evidence of a positive safeguards culture." For example, if a State performs independent audits and inspections, which are recommended but not required by the IAEA, these can help a facility resolve questions or anomalies before an international inspection is conducted. Such voluntary activities can reduce the expenditure of resources and time addressing questions during an international inspection. Facility management may encourage certain types of behavior because these behaviors benefit the mission in some way, either financially or operationally. Such encouragement comes in the form of professional advancement, financial reward, praise, recognition, or personal enhancement. These incentives help promote staff adherence to safeguards laws and regulations.

\subsubsection{Safeguards Culture within the IAEA}

This section lists potential indicators of safeguards culture within the IAEA. The 2005

INMM/ESARDA workshop in Santa Fe explicitly addressed the evolving safeguards culture at the IAEA. There, participants observed that (INMM 2006) "Over the last five years, the work of IAEA inspectors

\footnotetext{
${ }^{1}$ For Security concerns the U.S. Nuclear Regulatory Commission requires in security plans a reporting channel to the top level of plant management, not to mid-level management, and there has to be protection for anyone raising a concern.
} 
has changed dramatically from doing mostly verification activities at facilities to also conducting complementary access, reviewing additional State declarations, and preparing State evaluation reports." To conduct State-level evaluations, the role of the IAEA extends beyond traditional nuclear material accountancy.

This observation makes two important points. First, the evolving safeguards culture at the IAEA Secretariat is fundamentally different from the safeguards culture one recognizes in Member States. The safeguards mission of the IAEA Secretariat is not to comply with safeguards obligations as it is for Member States. It is to assure the international community that Member State nuclear activities remain dedicated to peaceful uses. As a result, safeguards culture within the IAEA Secretariat is different from a Member State's safeguards culture; it serves a different purpose. Rather than reflecting organizational attitudes and beliefs about safeguards, the safeguards culture at the IAEA is, or should be, designed to promote more effective and efficient implementation of safeguards. As verification responsibilities increase without a commensurate increase in budgetary resources, the need for a cultural change at the Agency has become urgent. For example, a cultural change (e.g., structural realignment) that promotes cooperation across organizational boundaries within the IAEA Secretariat will improve the process of using information to support safeguards conclusions. As another example, integrated training for inspectors and analysis on use of non-technical data to support safeguards conclusion will provide a more complete picture of Member State nuclear programs.

Table 4.2 demonstrates how certain indicators could be used to identify progress in making a cultural shift away from criteria-based inspections to more effective and efficient implementation of safeguards.

Table 4.2. Sample Indicators of the Evolving Safeguards Culture at the IAEA

\section{Indicators}

- Structural realignment supports greater cooperation and integration among inspectors, analysts, and support staff.

- Training in nontraditional methods and techniques such as foreign languages, forensics, negotiations, information analytic techniques, and investigation skills enable more effective safeguards analysis.

- Recruitment of staff with nontraditional skill sets supports more effective safeguards analysis.

- Incorporation of advanced information analytic tools supports more effective and efficient information analysis about Member State activities.

- Integrated training for safeguards inspectors and analysis on use of non-technical data to support safeguards conclusions.

\subsection{How might safeguards culture develop or be promoted?}

The benefit of clarifying a definition for safeguards culture and creating a framework for thinking about it is that the framework could be used to identify methods for promoting a strong safeguards culture within a Member State. Table 4.3 provides an expansion of Table 4.1 and lists a number of activities that could be pursued by a State (or promoted by third parties) to develop a strong safeguards culture within a State. 
Table 4.3. Sample Indicators of Safeguards Culture with Promotional Activities

\begin{tabular}{|c|c|}
\hline Safeguards Culture Indicators & Development/Promotion Activities \\
\hline $\begin{array}{l}\text { SRA is independent from organizations } \\
\text { responsible for promoting nuclear power. }\end{array}$ & $\begin{array}{l}\text { - State: Establish an independent regulator } \\
\text { - Third party: Encourage establishment of } \\
\text { independent regulator as a good practice }\end{array}$ \\
\hline $\begin{array}{l}\text { - SRA conducts independent inspections } \\
\text { - State and facilities perform regular self- } \\
\text { assessments to identify and resolve issues and } \\
\text { inconsistencies before the official inspection. }\end{array}$ & $\begin{array}{l}\text { - State: Conduct independent inspections and } \\
\text { self-audits. } \\
\text { - Third Party: Provide model self- } \\
\text { assessment/audit tools and methodologies. }\end{array}$ \\
\hline $\begin{array}{l}\text { State's nuclear suppliers and facilities share } \\
\text { nuclear export/import information with other } \\
\text { States to ensure all sales remain dedicated to } \\
\text { peaceful use; industry follows good corporate } \\
\text { governance and self-regulation practices. }\end{array}$ & $\begin{array}{l}\text { - State: Promote self-regulation practices among } \\
\text { industry companies; reward corporate } \\
\text { commitment to nonproliferation. } \\
\text { - Third Party: Establish working groups for } \\
\text { sharing shipment requests. }\end{array}$ \\
\hline $\begin{array}{l}\text { Mechanisms for reporting wrong-doing exist } \\
\text { and staff personnel use them, as evidenced by } \\
\text { clear reports generated by staff. }\end{array}$ & $\begin{array}{l}\text { State: Establish anonymous tip centers/lines; } \\
\text { reward self-reporting. } \\
\text { Third Party: Encourage staff/self-reporting } \\
\text { during training workshops. }\end{array}$ \\
\hline
\end{tabular}

\subsection{What is the relationship between safeguards culture, safety culture and security culture?}

Finally, we conclude our analysis of safeguards culture with an examination of its relatively slower development, as compared to nuclear safety culture and nuclear security culture. We explore the similarities and differences between each concept's development to help explain why safeguards culture as a concept has not matured, despite a number of noncompliance-related activities that might otherwise have driven further development of the concept.

We believe that perceived risk plays a critical role in the evolutionary process. As the world became more knowledgeable and experienced with operating nuclear power plants, countries became more cognizant of the risks associated with a nuclear accident. The level of risk associated with an event is determined by the probability it will occur and the consequences of that event. Naturally, when accidents at Three Mile Island and Chernobyl occurred, international concerns about the risks associated with nuclear power increased. In response, the nuclear industry began strengthening nuclear regulations to mitigate the risks. In conjunction with these efforts, they began considering ways to cultivate a culture that promotes greater appreciation and commitment to nuclear safety.

Over the years, as managers promoted safety, staff developed a shared belief in the importance of the objective and its ability to enhance operations. This positive attitude toward nuclear safety generated a way of doing business that emphasizes its overriding importance. Posters and signs commend and implore safe operational practices; advocate self-reporting of safety violations (without fear of retribution); and make clear statements about its high priority. 
Concerns about the risk associated with nuclear security have not evolved as quickly, but have increased steadily over the last two to three decades with incidents of nuclear materials theft by facility insiders in Russia and elsewhere. After the events of September 11, 2001, concerns about the risk of nuclear terrorism grew dramatically, and the attention paid to development of security culture grew as well. However, the perceived risk associated with nuclear terrorism and insider theft or sabotage remains an abstract problem to most people. A theft of nuclear material from a nearby facility will not necessarily have the same type or level of impact on the community or facility staff as would a nuclear accident. A person's perceived level of risk is directly proportional to the belief that he will be directly affected by the consequences. Thus, the importance stakeholders place on nuclear security objectives has been slower to penetrate certain facilities' cultures.

This perception of risk has played a similar role in the debate about whether to define and promote safeguards culture. The perceived risk to an individual from the diversion of nuclear materials or clandestine development of nuclear capabilities is comparatively low. Unless an individual were directly responsible for the theft or diversion, it is difficult to imagine how he or she might be affected personally if material were found missing from the facility or if clandestine nuclear facilities were revealed. This individual detachment from the consequences of State diversion or misuse of nuclear materials has made development and promotion of strong safeguards cultures more difficult. This may explain why some noncompliance events, which might have been expected to promote stronger safeguards cultures, have not created a groundswell of support for paying attention to the safeguards culture. As long as safeguards culture was linked to risk and by extension noncompliance, its further development and promotion would be unlikely.

However, mission effectiveness and efficiency are becoming equal priorities with risk mitigation, both within Member States developing nuclear power and within the IAEA. The IAEA has discovered that it cannot perform all of its responsibilities without introducing more efficiency into its operations, and nuclear newcomer States are learning that weak adherence to regulations, poor quality measurements, untrained staff, limited cooperation with the IAEA, and inaccurate accounting and operating records can all lead to an increase in IAEA scrutiny and greater intrusion in facility operations. In addition, safeguards problems can lead directly to safety and security concerns, which can have direct impact on operations as well as the safety and health of facility staff. Consequently, States are starting to assess the cost-effectiveness of optimizing organizational operations through the integration of complementary components of safety, security, and safeguards systems. The first opportunity to test the feasibility of integrating and optimizing $3 \mathrm{~S}$ measures is during the design process. With further scrutiny, we may discover that considering $3 \mathrm{~S}$ culture would provide new ways of promoting safeguards, safety, and security. 



\subsection{Definitions}

This section presents established definitions for safety culture and security culture and lists proposed working definitions for safeguards culture.

\subsection{Safety Culture}

In his paper for the 7th Joint INMM/ESARDA Workshop at Aix en Provence, Naito provides an extensive history and analysis of the definitions of safety culture, security culture, and safeguards culture. He notes (Naito 2011) that the first use of safety culture was in the initial report of the International Nuclear Safety Advisory Group (INSAG), Summary Report on the Post-Accident Review Meeting on the Chernobyl Accident (INSAG-1). INSAG has published a number of volumes describing Safety Culture (INSAG-4), Safety Principles (INSAG-3), Developing Safety Culture in Nuclear Activities (INSAG-13), and Practical Issues in Strengthening Safety Culture (INSAG-15). These all quote the definition published in INSAG -4, repeated here (INSAG 1991):

"That assembly of characteristics and attitudes in organizations and individuals which establishes that, as an overriding priority, nuclear plant safety issues receive the attention warranted by their significance."

In her paper at the First International Workshop on Safety and Security Risk Assessment and Organisational Cultures in January 2012, Monika Hagge, from the Operational Safety Section of the IAEA, noted that the IAEA Glossary listed a slightly revised definition that widens its application and that has since been incorporated into subsequent safety series documents (Hagge 2012).

"Safety Culture is that assembly of characteristics and attitudes in organizations and individuals which establishes that, as an overriding priority, protection and safety issues receive the attention warranted by their significance"

\subsubsection{Nuclear Security Culture}

The IAEA definition of Nuclear Security Culture is listed in the IAEA Security Series No. 7, Implementing Guide (IAEA 2008):

"The assembly of characteristics, attitudes and behavior of individuals, organizations and institutions which serves as a means to support and enhance nuclear security."

\subsubsection{Safeguards Culture}

In his paper at the 31 st meeting of ESARDA, noting that there was no internationally accepted definition for safeguards culture, Mladineo (2009) proposed the following definition:

"A shared belief among individuals, organizations, and institutions that international safeguards is an important undertaking to prevent the proliferation of nuclear explosives, which is manifested by strict attention to safeguards requirements and affirmative cooperation with safeguards authorities." 
Frazar and Mladineo (2010b) later refined Mladineo's definition to more strongly emphasize the contribution to mission:

"A shared belief among individuals, organizations, and institutions that strict attention to international safeguards requirements and affirmative cooperation with safeguards authorities will enhance their nonproliferation stature and benefit their missions."

Kovacic and his co-authors (Kovacic et al. 2009) proposed the following definition:

"A unifying commitment by an organization and its members to the effective and continuously improving implementation of material control and accounting practices; the prevention of misuse of facilities; and prevention of the dissemination of sensitive technology. It also includes not just the establishment and enforcement of strong regulatory requirements but also voluntary adherence to standards, best practices, and self-evaluation aimed at non-tolerance of mistakes or deliberate disregard. Therefore, safeguards culture has to be inherent in the thoughts and actions of all the individuals at every level in an organization and must be supported by top management."

Naito argues that the definition of safety culture emphasizes its overriding priority, and the definition of nuclear security culture is silent about the relative priorities among nuclear security, safeguards, public acceptance, transparency and other factors. With this in mind, he writes that it is hard to say that nuclear security should have overriding priority and that this may hold true for safeguards. He proposes to define safeguards culture after nuclear security culture (Naito 2011):

"The assembly of characteristics, attitudes and behavior of individuals, organizations and institutions which serves as a means to support and enhance safeguards or to achieve effective and efficient safeguards."

Arguing that there needs to be measureable artifacts to make the definition more practical, Karyn Durbin of the National Nuclear Security Administration has proposed another definition of Safeguards culture:

"Safeguards culture is a shared belief, as manifested in decisions and actions, by individuals, organizations, and institutions that affirmative cooperation with IAEA safeguards authorities will benefit their missions."

Despite the similarities among these definitions, we identified one with a key differentiator. Naito's definition focuses on the IAEA mission (effective and efficient safeguards), but it also has the State-level safeguards culture component (support and enhance safeguards). By parsing his definition, we can clarify the difference between the two senses or usages of safeguards culture. Consequently there may be merit in considering a separate definition for IAEA safeguards culture, such as:

A shared belief by IAEA safeguards authorities, inspectors, and analysts that the people, processes, and procedures used by the IAEA to draw safeguards conclusions are effective and efficient.

Each definition addresses individuals, organizations and institutions, either explicitly or implicitly. Each considers aspects of organizational culture and emphasizes beliefs, attitudes, and behaviors or activities. While each author may have slight preferences for one word or phrase over another, the

${ }^{1}$ Durbin, K. 2011. Subject: Definition, Email message from Karyn Durbin (NNSA) to Sarah Frazar and Stephen Mladineo (PNNL), October 20, 2011. 
definitions all get at the crux of the issue: A strong safeguards culture is one in which the beliefs, values, and attitudes toward international safeguards encourage more effective and efficient behavior. In a State, such behavior promotes compliance with national and international laws, regulations, and requirements.

In the IAEA it promotes effectiveness and efficiency.

\subsubsection{S Culture}

For completeness, we propose a definition of 3S Culture (Frazar and Mladineo 2011b):

A widely shared belief that the Mission of the Organization is enhanced by an institutional and individual commitment to Safety, Security, and Safeguards. 



\subsection{Next Steps}

Further exploration of safeguards culture should begin with achieving an international consensus on a definition for the concept. This should be followed by development of a rigorous methodology for identifying indicators of safeguards culture and establishing the causal link between beliefs or attitudes and safeguards actions. These indicators should offer the IAEA objective, factually based information that does not discriminate among States. This conceptual development will help inform establishment of a clear definition for safeguards culture, which is necessary to advance discussion among Member States and promote good practices that improve safeguards performance.

Specifically, the authors recommend several follow-on activities to support further exploration of safeguards culture.

- Following Naito's suggestion, the IAEA should ask SAGSI take up the issue of formalizing a definition for safeguards culture.

- Another approach would be for the IAEA to invite a group of safeguards experts to consult on a definition for safeguards culture.

- An IAEA consultants' meeting should be convened to develop a rigorous methodology for considering the indicators of safeguards culture.

- NNSA or the IAEA should explore lessons learned from promoting safety culture at facilities to identify potential linkages to safeguards.

- NNSA or the IAEA should sponsor a workshop for Member States to explore the feasibility of promoting better safeguards awareness at facilities; NNSA or the IAEA should prepare a report on good, common practices that promote strong safeguards cultures.

- NNSA or the IAEA should conduct a related study that details specific activities at the IAEA that promote effective and efficient safeguards implementation.

- NNSA should consider exploring the merits of $3 \mathrm{~S}$ cultures; considering regulatory approaches and good practices that promote synergies among safety, security and safeguards.

- PNNL should present an abbreviated version of this paper at the INMM and subsequently at an ESARDA meeting to get feedback from the international safeguards community. 



\subsection{References}

Carlson J. 2010. "Strengthening Safeguards through Regional Cooperation: Establishment of the Asia Pacific Safeguards Network," Proceedings of the $50^{\text {th }}$ Annual Meeting of the Institute of Nuclear Materials Management, Tucson, AZ, 11-15 July, 2010, Institute for Nuclear Materials Management, Deerfield, Illinois.

Carlson J. 2012. "Innovating Nuclear Security Governance." Conference on the 2012 Seoul Nuclear Security Summit And Next Generation Nuclear Security, Seoul, 2 November 2011. Accessed July 6, 2012 at http://www.fmwg.org/seoul_presentations/john_carlson.pdf.

Carlson J. 2005. "Views on and Expectations from the Workshop." Proceedings of the INMM/ESARDA Workshop, Changing the Safeguards Culture: Broader Perspectives and Challenges, Santa Fe, New Mexico, October 30-November 2, 2005, Institute for Nuclear Materials Management, Deerfield, Illinois.

Cooley, JN. 2011. "Progress in Evolving the State-level Concept." Proceedings of the Seventh INMM/ESARDA Joint Workshop, Aix-en-Provence, France, 17-20 October 2011, Institute for Nuclear Materials Management, Deerfield, Illinois.

Cooley, JN and Howsley, R. 2005. "Reports of Working Groups." Proceedings of the INMM/ESARDA Workshop, Changing the Safeguards Culture: Broader Perspectives and Challenges, Santa Fe, New Mexico, October 30-November 2, 2005, Institute for Nuclear Materials Management, Deerfield, Illinois.

D’Agostino TP. 2009. Speech presented at the Second International Meeting on Next Generation Safeguards, Tokai-mura, Japan, October 26, 2009. Accessed July 5, 2012 at http://nnsa.energy.gov/mediaroom/speeches/presented-second-international-meeting-next-generationsafeguards.

Frazar SL and SV Mladineo. 2010a. "Defining and Measuring Safeguards Culture." Proceedings of the Pacific Northwest International Conference on Global Nuclear Security - the Decade Ahead, Portland, Oregon, April 11-16, 2010, Institute of Nuclear Materials Management, Deerfield, Illinois.

Frazar, SL. and SV Mladineo. 2010b. "Safeguards Culture: Lessons Learned.” ESARDA Bulletin, Number 44, June 2010.

Frazar SL and SV Mladineo. 2011a. "Measuring Safeguards Culture," 52nd Annual Meeting of the Institute of Nuclear Materials Management 2001, Palm Desert, California, USA, 17-21 July 2011. Institute of Nuclear Materials Management, Deerfield, Illinois.

Frazar SL and SV Mladineo. 2011b. "Safety, Security, and Safeguards (3S) Culture." Proceedings of the 7th Joint ESARDA/INMM Workshop, Aix en Provence, France, October 16-20, 2011. Institute for Nuclear Materials Management, Deerfield, Illinois.

Hagge, M. 2012. "IAEA approach to safety culture." Accessed July 6, 2012 at http://www.sckcen.be/en/Events/SSRAOC2012/\%28page\%29/41672. 
Institute of Nuclear Materials Management (INMM). 2006. "Report on 2005 INMM/ESARDA Santa Fe Workshop: Changing the Safeguards Culture: Broader Perspectives and Challenges" INMM Communicator, 3(3). Accessed on March 21, 2012 at https://www.inmm.org/communicator/winter 06/workshop.htm.

International Atomic Energy Agency (IAEA). 2008. Nuclear Security Culture, Implementing Guide. IAEA Nuclear Security Series No. 7, International Atomic Energy Agency, Vienna.

International Nuclear Safety Advisory Group (INSAG). 1991. Safety Culture. Safety Series No. 75-INSAG-4, International Atomic Energy Agency, Vienna. Available at http://wwwpub.iaea.org/MTCD/publications/PDF/Pub882_web.pdf.

Kondo S. 2009. “Japan's Nuclear Energy Policy and Nuclear Nonproliferation," speech presented at the Second International Meeting on Next Generation Safeguards, Tokai-mura, Japan, October 26, 2009. Accessed July 5, 2012 at http://www.aec.go.jp/jicst/NC/about/kettei/091026.pdf.

Kovacic DN, A Raffio-Caiado, J McClelland-Kerr, M Van-Sickle, M Bissani, and K Apt. 2009. "Nuclear Safeguards Infrastructure Development and Integration with Safety and Security." $50^{\text {th }}$ Annual Meeting of the Institute of Nuclear Materials Management 2009, Tucson, Arizona, USA,, 12-16 July 2009, Institute of Nuclear Materials Management, Deerfield, Illinois.

Martikka EH. 2012. "Evolving Safeguards Culture.” Accessed July 6, 2012 at http://www.sckcen.be/en/Events/SSRAOC2012/\%28page\%29/41672.

Martikka EH, T Honkamaa, and M Hamalainen. 2011. "SSAC Creating Safeguards Culture.” 52nd Annual Meeting of the Institute of Nuclear Materials Management 2001, Palm Desert, California, USA, 17-21 July 2011, Institute of Nuclear Materials Management, Deerfield, Illinois.

McClelland-Kerr J and R Stevens. 2010. "Building Safeguards Infrastructure," chapter in Nuclear Power and Energy Security, NATO Science for Peace and Security Series B: Physics and Biophysics, eds. S Apikyan and DJ Diamond, Springer, The Netherlands, DOI: 10.1007/978-90-481-3504-2_3.

Mirsaidov UM. 2010. "Implementation of the Safeguards System in the Republic of Tajikistan," IAEACN-184/090. Accessed July 5, 2012 at http://www.iaea.org/OurWork/SV/Safeguards/Symposium/2010/Documents/PapersRepository/090.pdf.

Mladineo SV. 2009 "Safeguards Culture: Lessons Learned." In Proceedings of the $31^{\text {st }}$ ESARDA meeting, Vilnius, Lithuania, May 26-28, 2009, European Safeguards Research and Development Association, Ispra, Italy.

Mladineo SV and S Frazar. 2012. "Organizational Culture, 3S, and Safeguards by Design.” Accessed July 6, 2012 at http://www.sckcen.be/en/Events/SSRAOC2012/\%28page\%29/41672.

Moreno SF. 2010. "Symposium on International Safeguards: Preparing for Future Verification Challenges." Accessed July 5, 2012 at 
http://www.iaea.org/OurWork/SV/Safeguards/Symposium/2010/Documents/PPTRepository/Fernandez.p $\underline{\mathrm{df}}$

Naito, K. 2011. "Progress in Evolving the State-level Concept." Proceedings of the Seventh INMM/ESARDA Joint Workshop, Aix-en-Provence, France, 17-20 October 2011, Institute for Nuclear Materials Management, Deerfield, Illinois.

Persbo A. 2012. "IAEA safeguards Symposium ends." Accessed July 5, 2012 at http://www.vertic.org/pages/posts/iaea-safeguards-symposium-ends-15.php.

Schein, EH. 1997. Organizational Culture and Leadership. 2nd Ed., Jossey-Bass, John Wiley \& Sons, San Francisco, California.

Scheinman AM. 2008. "Next Generation Safeguards Initiative," presented at the International Forum on Nuclear Nonproliferation and Peaceful Use of Nuclear Energy in the Asia Region, Tokyo, Japan, June 2425, 2008. Accessed July 5, 2012 at http://www.jaea.go.jp/04/np/activity/2008-06-24/2008-06-24-26.pdf.

Scheinman, AM. 2009. "Calling For Action, the Next Generation Safeguards Initiative." The Nonproliferation Review, 16:2, 257-267.

Szöllősi E. 2012. : Assessing and Promoting the Level of Safeguards Culture in Hungary, Case Study.” Accessed July 6, 2012 at http://www.sckcen.be/en/Events/SSRAOC2012/\%28page\%29/41672 




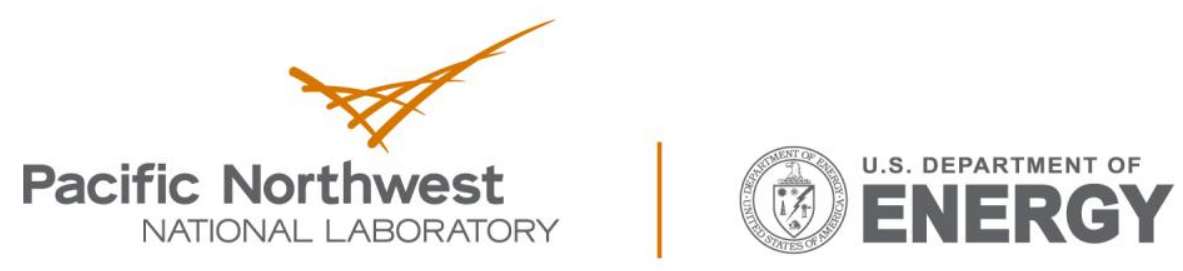

Proudly Operated by Battelle Since 1965

902 Battelle Boulevard

P.O. Box 999

Richland, WA 99352

1-888-375-PNNL (7665)

www.pnnl.gov 